\title{
Analysing Resistance of Stereotyped Sexuality via 'Gender Performance' in The Silk Fan and Under the Blanket
}

\author{
Nurul Soleha binti Mohd Noor (Corresponding author) \\ English Department, Faculty of Modern Languages \& Communication, Universiti Putra Malaysia, Malaysia \\ E-mail: soleha.mdnoor@gmail.com \\ Arbaayah Ali Termizi \\ English Department, Faculty of Modern Languages \& Communication, Universiti Putra Malaysia, Malaysia \\ E-mail: arbaayah@upm.edu.my
}

\author{
Received: 18-12-2016 \\ Accepted: 25-01-2017 \\ Advance Access Published: March 2017 \\ Published: 01-05-2017 \\ doi:10.7575/aiac.ijalel.v.6n.3p.219 \\ URL: http://dx.doi.org/10.7575/aiac.ijalel.v.6n.3p.219
}

The research is financed by Geran Putra - Inisiatif Putra Siswazah Project Number 9450300.

\begin{abstract}
Existing studies had shown that gender stereotyping is still evident in contemporary Malaysian English literature particularly in novels. By using the concepts of 'gender performance' and 'performativity' introduced by Judith Butler's Gender Trouble (1990), the current study aims to prove that there is an act of resistance among the new generations/contemporary Malaysian writers against the gender norms placed on sexuality. These writers resisted the norms by performing "gender trouble" through the construction of their characters' gender identity. Two short stories are selected from 25 Malaysian Short Stories: Best of Silverfish New Writing 2001 - 2005 as the scope of the study to answer these questions; (a) what are the stereotyped 'gender performances' of the characters' sexuality in the two selected short stories?, and (b) how do contemporary Malaysian writers resist stereotyped sexuality using 'gender performance' in their writings? The study found that the selected characters from the short story The Silk Fan and Under the Blanket, do perform "gender trouble" in resisting gender expectations on their sexuality. Thus, based on the results of this study, it is hoped that the misconceptions on gender and the conventional way of thinking about sexuality and gender in Malaysian society can be somewhat liberated.
\end{abstract}

Keywords: sexuality, stereotype, resistance, performance, performativity, gender trouble

\section{Introduction}

There are three generations of Malaysian writers in English as stated by Chin (2007) in a book chapter entitled New Generations Writers in English: Discursive Conditions and Literary Revival in Malaysia, 1996-2005. They are; (a) the pioneers, (b) the post-independence writers, and (c) the new generation writers (p. 262). These new generation of writers, which will also be regarded as contemporary writers in this paper onward, appeared only in the late 19th century. These writers come out with new literary ideas, themes and styles (p. 269) and they mostly explore controversial issues rather than the political one which is unlike the previous generations (p. 277). Not to mention, Malaysian writers are affected psychologically in terms of repressive methods they had to consider in writing. This is due to the tight censorial structures that had caused fear among them (p. 279) to write freely about what they genuinely think and feel. These contemporary writers also explore recurring issues such as cultural, gender, racial, and identity issues (p. 276).

Due to these arising issues among Malaysian society, Wignesan (1981) stated that Malaysians ought to deal with multicultural and multilingual challenges in Malaysia through the use of English language in conveying the right message in their stories (p. 77). Hence, among many other publishing companies, Silverfishbooks is an independent publishing house that had helped revive and sustain the short story writing tradition which highlights the above challenges starting from the year 2000 through the publication of its annual anthology, Silverfish New Writing. The anthology brought forward "new", never-before-published works of Malaysian, both new and established writers (Chin, 2007, pp. 272-273). In an interview with Raman Krishnan (the Silverfish New Writing series producer) conducted by Raihanah (2011), the producer declared that the main aim of the series was to provide Malaysians the opportunity to become owner of their own stories and to be able to represent the Malaysian voice (p. 62). The series, for this reason, portrayed a 'collective Malaysian consciousness' concerning local writers' voice and literary persona with a range of issues such as multiculturalism, gender, race and politics (Raihanah, 2011, p. 63).

In 25 Malaysian Short Stories: Best of Silverfish New Writing 2001 - 2005, various issues of identity formation and complexities are presented through numerous evidences of personal script literary representation especially with the use of first person point of view style of writing (Raihanah, 2011, p. 64). Consequently, the personal Malaysian voices are 
represented in this collection through these personal scripts by displaying the identity of the characters (p. 65). As mentioned by Gauntlett (2002), nothing within our identity is fixed since identity is the product of social and cultural repetition of discourse. Thus, traditional views of masculinity and femininity should be challenged because gender, like identity, is a mere performance (p. 135). Accordingly, writings (literatures) are influenced by gender and social construction of traditional 'norms' that had been set for both male and female (Goodman, 1996, p. 72).

It was found by Hashim et al. (2011) that contemporary Malaysian women writers had highlighted the issues of Malysian women being affected by modernity and fast development in Malaysia (p. 395) in a study conducted to uncover the realities of Malaysian women through their writings that may act as means for change (p. 392). The study also indicated that "these women experience acute loneliness, psychological and emotional drifting apart. They are oftentimes disillusioned over urban life and love with its various forms of cruelties" (396) placed on them by the society itself. It is understood here that contemporary Malaysian women suffer from the expectation of the society placed on them to be accepted in modern Malaysia. Other than that, Raihanah (2009) discovered that Malaysian writers in English have various concerns at hand especially on the issue of multicultural identity due to the diversity of Malaysians in terms of race, culture, and even gender (p. 56). It is asserted later in the study that these challenges of multiculturalism can be met through cross interactions of writers' "personal needs, ethnic-cultural needs, and national needs" (p. 60). It appears that society is still at large responsible for shaping people's needs and desires. The previous studies had showcased the issues that had been faced by contemporary Malaysian writers in writing their stories. The social expectations that had been placed on them are seen to be oppressive in nature and there is a strong commitment in these writers to subvert the societal pressures.

This paper will focus its attention on the contemporary writers and their short stories. This is because through literary representation, it offers a way for readers to deconstruct the issues and concerns at hand since literature stands for a creative representation of a country's development at a specific time in history (Raihanah, 2011, p. 61). The current paper aims to prove that there is an act of resistance among the contemporary Malaysian writers against gender norms placed on sexuality by performing "gender trouble" through the construction of their characters' gender identity in their short stories. Two short stories are selected from 25 Malaysian Short Stories: Best of Silverfish New Writing 2001 2005 as the scope of this paper in an attempt to answer these questions; (a) what are some of the stereotyped 'gender performances' of the characters' sexuality in the two selected short stories?, and (b) how do contemporary Malaysian writers resist stereotyped sexuality using 'gender performance' in their writings? These two short stories are selected out of the 25 stories because of the similar sexual issues presented in them. The next section will discuss the significance of the concepts and categories chosen as theoretical method embedding this paper.

\section{Theoretical Framework}

Gender Trouble (1990) was written by Judith Butler to present the collective struggle of sexual identity as part of the cultural life (Butler, 1990, p. xxviii). She presented the concepts of 'gender performance', 'gender performativity', and 'gender trouble' in this book to explain this struggle of sexual identity.

'Gender performance' is a creation of norm by cultural fiction that obliges people to perform gender in the belief that it is natural and necessary. With that, punishment awaits for those who did not perform their gender right (Butler, 1990, p. 190). This is supported by Castle's (2007) explanation of 'performance' as; the social norms and mystification of sexual identity. And that gender was formed through the ideals of philosophy, religion, psychology, medicine, and popular culture (p. 104). In the current study, it is conclusive to say that 'performance' is what the gender ideologies had assigned to people on what constitutes gender. Whereby, this means that the female and male gender roles are merely the products of this very concept of 'gender performance'.

'Gender performativity', on the other hand, is how we carry out the norms that had been created by this cultural fiction. It is a constructed identity where the people who had come to believe the norms chose to perform them in the mode of the belief (Butler, 1990, p. 192). As elaborated by Ryan (2007), 'performativity' is the repetitive imitation of the normal gender standards of 'performance' (p. 135). This indicates how people carry out the 'performance' of gender is their 'performativity' of that gender. It is the gender discourses of the people in performing the gender norms that had been assigned to them as their beliefs system.

According to Butler (1990), the book is written as an effort to replace and challenge the traditional beliefs of gender by performing 'gender trouble'. This is done in order to go against the misrepresentations of gender identity that had been repetitively imposed by the norms of compulsory heterosexuality (p. 46). Hence, 'gender trouble' is a method that can be used to resist gender stereotyped norms. By troubling gender, people can choose not to repeat gender norms (Butler, 1990, pp. 202-203) and this will make way for a better representation of gender identity rather than the traditionally imposed identity. 


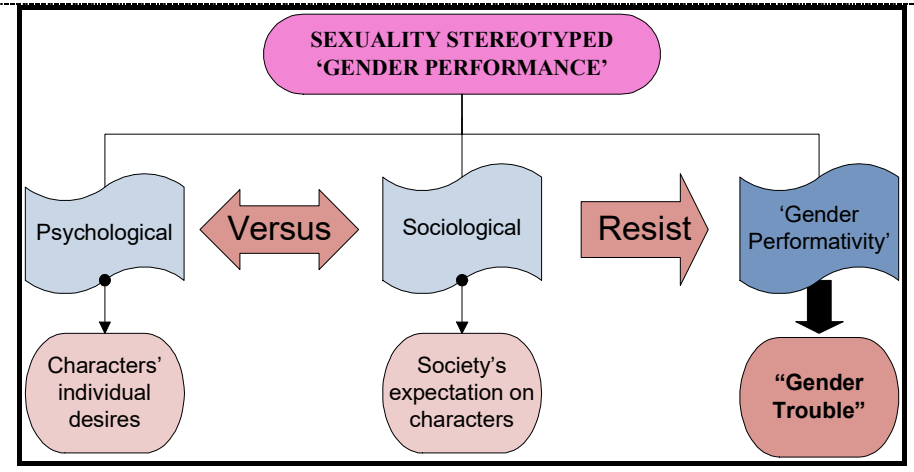

Figure 1. The Stereotyped Sexuality ‘Gender Performance’ Resistance Flowchart

As depicted in Figure 1, the concept of 'gender performance' is in relation to the ideologies of gender assigned to male and female characters in the short stories that took a deep root into their psychological and sociological make up. The psychological aspect of the characters is their personal conflicts within themselves of which they have their individual desires to commit the forbidden. On the other hand, the sociological perspectives would be the characters' responsibilities to carry out gendered norms that had been placed on them by the society in order to fit into certain social statuses. Meanwhile, the concept of 'gender performativity' is the discourse of gender through the characters' actions and conversations. These ideologies are conflicting against personal desires of the characters. How these characters discourse against the ideologies from the selected short stories will be analyzed by looking at the way these characters give in into their individual desires rather than conforming to act in accordance to their gender roles set by the society. By resisting the gender norms, the characters had, therefore, performed "gender trouble".

Throughout history, sexuality had always been a subject of silence and shame. According to Mollon (2008), sexuality is usually repressed or taken out completely from discourse due to its' fundamental cause of threats and frights. It is often only referred to indirectly (p. 24). For the most part, sexuality is especially threatening and frightening to masculinity rather than femininity. This is due to the idea of reason and control that had long been associated to masculinity. This is supported by Seidler (1995) that "issues of sexuality are potentially threatening because they challenge the ideals of control which a rationalist culture has continued. Just as emotions and feelings are treated as mental phenomena, so are sexual desires" (p. 91). Therefore, male's sexuality had been silenced for the very purpose of control that lies in the idea of their masculinity.

However, the purpose of silence for female's sexuality differs from male. If a male's sexuality revolves around the idea of being in control, then, a female's sexuality had been silenced in order to be controlled. The males need to be in control of females so that sexuality will remain as a subject of silence and shame. To ensure the continual of this control-and-being-controlled purpose of sexuality between male and female, the society (which normally a patriarchal one) puts forward the convention of marriage. As stated by Wisdom (1992) "to discuss woman and man, and enter upon the fringe of society, we cannot leave societal matters without some remarks on marriage ... Every community or tribe must have marriage laws or customs otherwise the group could not survive" (p. 110). The marriage convention is set as a law for the purpose of none other than survival and decency to avoid unwanted pregnancies and sex before marriage. This is because the continual of the species is the most important aspect of sexuality. As further elaborated by Wisdom (1992) that "man is given pride of place over woman, for without defence there can be no secure procreation" (p. 110). It is the sexual role of the females to procreate while males to defend.

Nonetheless, it is in the nature of humans to strive for pleasure and freedom. This had always taken its reference to psychoanalysis as the basis of discussing people's unconscious desires. According to Phillips (2015), "psychoanalysis could help us forget the self, and help us talk about conflicting desires and punitive internal authorities instead; or competing pleasures; or competing evaluations of pleasure, a Death Instinct that wants to destroy the possibility of pleasure, and a Life Instinct that will go to great lengths to sustain pleasure" (p. 34). This means that personal desire for pleasure, no matter how destructive or prohibitive that is, existed in all human beings and we are constantly in battle between giving in to this pleasure or putting it to rest. Phillips (2015) also stated that our actions in obeying an order (in this sense, social prohibition) will define who we really are (p. 49). Therefore, how we perform what 'gender performance' had decided for us will determine our true self. Of course, this is in accord to whether we choose to obey the roles of gender or disobey them altogether.

Butler (1990) had frequently theorized how gender is 'performative' and that there is no pre-existing gender identity before the compulsion of imposed gender ideologies. Gender reality is only constructed through sustained repetitive social 'performances'. Therefore, it is possible for people to perform differently than the imposed norms of the compulsory heterosexuality (p. 192) by performing "gender trouble". Through the resistance of stereotyped 'gender performance' of these writers, the need to change the conventional way of thinking about gender will be enlightened. The literature review of past studies that had been done by other scholars through the similar concept of 'gender performance' and 'gender performativity' as depicted in various types of literature will be explored in the next section of this paper. 


\section{Literature Review of Relevant Past Studies}

Butler's concepts of 'gender performance' and 'performativity' had been utilized by previous scholars outside of Malaysian perspective to look at the subversion of gender norms by fictional characters in various literary mediums. Some of the mediums are novels and plays. This section intends to look at these studies to better understand the findings of the past studies which had led to the significance of current study.

A study conducted by Bauer-Gatsos in 2002 applied the concept on Victorian novels to examine the connection between the roles of individual writers who are both reviewers and novelists (p. 6). The study found that women writers resist the laws on gender by reiterating the issues they saw from previous novels that they had reviewed in their own narration of their novels (Bauer-Gatsos, 2002, p. 200). On the other hand, Williams (2009) conducted a study using the concept to interconnect women's unexpressed discourse and experience between three novels and an autobiography. The results showcased that the texts chosen question and deconstruct migration as an idealized process of selfactualization on Asian immigrant women (pp. 13-14). Both of these studies portrayed how real life can influence the narration of writers in dealing with gender issues in a society.

Other than that, some studies had been done by scholars through similar concepts presented by Butler on plays and playtexts. Solomon (2001) found that the protagonist in the play Coriolanus possessed an unstable gender identity through his performativity due to the distorted portrayal of masculinity in the play that the protagonist had to go through (p. 106). Meanwhile, in examining the ways in which a play could provoke critical reaction by audiences on the circumstances faced by gay characters (p. 4), Gorney (2003) uncovered that the play Angels in America deconstructed the stereotypes on gay marginalization by empowering femininity in gay characters rather than masculinity in order to marginalize instead the gay characters who succumbed to heteronormativity through their gender performativity (p. 75). These studies showcased how the concept is useful in discovering subversion of gender through literature.

Nonetheless, the scope of the study had been studied by Raihanah Mohd Mydin in New Writings in Malaysia: Issues and Concerns in 2011. The chapter was written to discuss the issue of multicultural identity construction in Malaysian literature (Raihanah, 2011, p. 59). Raihanah (2011) found that there are two scripts being used by the Malysian authors. One is social and the other is personal. She asserted that "the primary concern of the emerging writings in Malaysia, unlike their established predecessors, rests on developing a personal and private voice at the expense of a more social one. ...the emergent writings in the country signal a move towards defining a stronger individual voice rather than a purely collective one" (p. 67). The story Under The Blanket was discovered to be utilizing a strong sense of personal script where it deals with a "young child's innocence and emotional development" (Raihanah, 2011, p. 64) while the story The Silk Fan used a social script in investigating "the moral problems of the more communal culture such as filial obedience and the importance of socio-cultural attachments and social hierarchy" (Raihanah, 2011, p. 65).

However, the current study will look at the issues of gender as represented in the scope. The paper attempts to utilize the concept of 'gender performance', 'gender performativity', and 'gender trouble' on short stories instead of other literary mediums. The study will also focus on Malaysian literature to better view how Malaysian society deals with the construction of gender reality. Through the characters, the writers are presumed to sublime their effort in resisting gender roles that had been imposed on individuals by the society. To prove that Malaysian contemporary writers in English are 'gender troubled', textual analysis of the chosen short stories is enlightened in the following section.

\section{Portrayal of Resistance for Stereotyped Sexuality via 'Gender Performativity' in The Silk Fan}

As illustrated in the previous section the stereotyped norms stereotypically for males are to defend females while females procreate. And the law of marriage had been invented precisely to keep this stereotype in check. Despite the expectation from the society for people to abide by this gender role, it was found that the characters in the selected short stories resist against the norms. As an example, incestuous rape occurs in The Silk Fan between the protagonist's mother and her uncle;

"Stupid, stupid girl!" she cried out again, her voice changed from deep to shrill. "How I tried to protect you by calling her an autumn fan. The truth is worse than that, you stupid, stupid girl! Now I have to let you know!"

"What is there to know?" Lin Lin demanded, the heavy sense of foreboding that had dogged her all her life surfacing as a tight feeling in her chest. Ah Kim released her suddenly, making Lin Lin stagger a step backwards. The dark eyes bored into her, her deep voice turned shrill.

"Your uncle was your natural father. Now you know." (Cean, 2006, p. 87)

In the story, the protagonist was brought up not knowing that she was the child of her own uncle with her mother from an incestuous rape. She was furious that her deceased mother was treated badly by her uncle's wife that she wanted to humiliate her during her uncle's funeral. She however found out the truth about her birth in the end. The excerpt above shows how the male character had resisted the societal roles for men to defend women. The male character from this story had violated his own sister which had led her to give birth to a child out of wedlock.

Incestuous rape is seen as a form to inflict power on someone less powerful as a result of being oppressed as seen by Koopman (2013) in her study on two novels that portray incestuous rape of a father to a daughter (p. 2). Despite of the fact that previous studies had indicated that incestuous rape was used in order to broadcast male domination on women 
(Salter, 2013, p. 161), the current study differs in terms of the idea that incestuous rape is committed in order to rebel against the gender roles that had been imposed on males. This is due to the agreed fact that incest is, as cited in Koopman (2013), seen as a "universal" taboo (p. 3). Committing it suggests that the proprietor had subverted against the most ancient gendered norms produced by the society and the most forbidden form of sin.

As for the female character from the story, the protagonist's mother is deemed appropriate to depict resistance against the norms. The protagonist's mother was called as 'an autumn fan' which is a term for a deserted woman for giving birth to the protagonist out of wedlock. This had made the protagonist never knew who her real father is all her life;

It became her obsession because those words reflected what she, Lin Lin, was to be. She was a child of a deserted woman, a woman cast aside, unwanted. She was the unwanted, abandoned child of an unknown father. Only the thought of her uncle's charity made her patient to wait all these years. (Cean, 2006, p. 85)

The excerpt from the story proves how the female character did not follow the rules of marriage by giving birth to a child out of wedlock. This, therefore, defeats the purpose of procreation under the marriage law. The protagonist in this short story is an incestuous offspring. Without her even realizing it, it is due to this that she had always felt rejected. In some way, what she feels is also similar to what her mother had felt as a victim of an incestuous rape. Her mother had passed away due to the alienation she was cast upon by her family members and also of her own heartbreak from the violation imposed on her. As Koopman (2013) had argued that "the incest victim is cast off by her own family" (p. 12) and also that "a victim of incest stands alone" (p. 17). Though both Lin Lin and her mother are victims of incestuous rape and it was something out of their control, Lin Lin's mother had chosen to keep the baby. Keeping an incestuous offspring shown how she had subverted against the societal norms that pregnancy and procreation are strictly only allowed in marriage. She had given birth to a child without marriage and from an incestuous union as a way to deny gender roles of women to be sexually controlled by marriage.

\section{Portrayal of Resistance for Stereotyped Sexuality via 'Gender Performativity' in Under the Blanket}

Incestuous rape also occurs in the short stories Under the Blanket. The story was written in first person narration of the protagonist who is sexually abused by her uncle. According to Raihanah (2011); "the personal script in this story highlights the young child's innocence and emotional development" (p. 64). In the story, the male character, which is the protagonist's uncle, molested his own niece;

Sometimes when its real late and mummys gone to bed he likes to come in my room and play with my hair and tell me stories and say how pretty I am. I used to like that but I dont anymore because last time he came he smelt all funny like mr Chan next door who has all the cans and bottles in his dustbin an mummy says he is an al keyholic. Uncle Jay made me take off my pajamas, they have got teddy bears on them. Then he touched my down there an said I was real bootiful and that I coodnt tell anyone about this, its our little secret. That its perfekly normal for him to touch me down there. (Alkaf, 2006, p. 69)

This shows how the male character from the story resists to the stereotypical role of defending women by abiding to the law of marriage. By committing incestuous rape, Uncle Jay, similarly to Lin Lin's uncle from the previous short story The Silk Fan, had committed the most forbidden sexual acts and had therefore defiled gendered norms that had been placed on him.

Nonetheless, the protagonist subverts towards the sexual abuse inflicted on her by not being silence about what her uncle did to her as she tried to tell her mother about it;

But I cryed and cryed anyway coz I felt so funny an scared. So he went away. I tried to tell mummy after that but she just laffed an said I was dreaming, that it was another Fayze like the one with the monsters an that I had an overaktivve imajinashun. She said I shoodnt say things like that about uncle Jay because hes helped us a lot and hed be real hurted if he knew. (Alkaf, 2006, p. 69)

This shows that though sexuality is a subject of shame and silence, the protagonist of the story resisted towards the male's violation on her by not letting herself being subjected to silence with an effort of telling an authoritative figure about it despite of the fact that she was not believed in.

It was found by Villani and Lopes (2014) in a film review involving a paedophile sexual abuse on young boys that "the voice of the child becomes a suppressed current resting in a supposed incapacity to securely access the sense or create a sense for their experiences in general, but in particular, sexual" (p. 713). By voicing out the abuse, the protagonist child in Under the Blanket had subverted against the norms of her gender to be silenced about her sexuality despite of the common stereotyped beliefs as indicated by Villani and Lopes (2014) that there is no such existence of childhood sexuality due to the idea that children are innocence and devoid of sexuality (p. 713). The protagonist had tried to prove to her mother that children are also prone to be exposed to sexuality especially by an unsuspecting paedophile. 


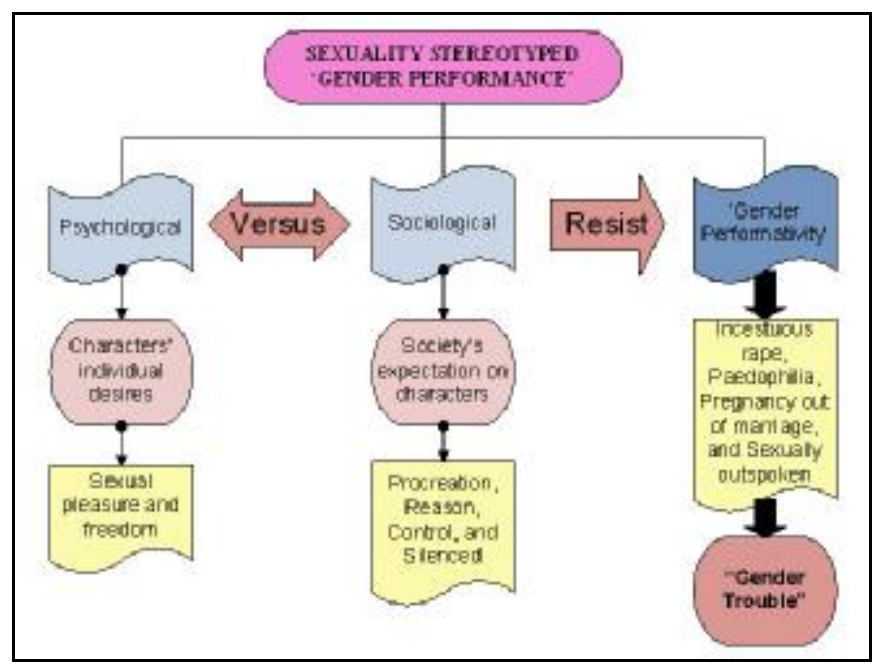

Figure 2. The Stereotyped Sexuality 'Gender Performativity’ Flowchart

As shown in the diagram above, the 'gender performance' ideology had inculcated on both genders to abide the law of marriage strictly for defense and procreation. However, it was proven that both genders had defiled their gender roles through their 'gender performativity' by committing incestuous rape. Sexuality is also not as silenced as it should be due to the characters' protest of the roles subjected to them. The research questions of the paper had gained their answers that (a) some of the stereotyped 'gender performances' of the characters in the two selected short stories are the expectation for them to follow the norms of marriage (to procreate) and being silenced about their sexuality (for order and control), and that (b) contemporary Malaysian writers resist stereotyped sexuality norms in their writings through 'gender performativity' of the characters whom had given in to their personal desires for sexual pleasure and freedom by committing incestuous rape, giving in to paedophiliac desire, giving birth to a child out of marriage, and also not submitting to silence. Thus, it was proven that Malaysian writers are "gender troubled" through the construction of their characters' sexuality in the short stories' narration and characterization. As the main aim of the paper is to show that contemporary Malaysian writers are resisting against the societal norms placed on gender, their writings of the most taboo sexual disobedience as incest had portrayed how empowering it is for them to "trouble" gender. Though this was only written in the form of fiction, it is nothing but only a reflection of reality or of a desired reality. It is hoped that based on the results of this paper, the conventional way of thinking and performing gender in Malaysian society can be further reconstructed and deconstructed to promote the possibilities of a fluid gender identity.

\section{References}

Alkaf, H. (2006). Under the Blanket. In Sivagananam, N. (Ed.), 25 Malaysian Short Stories: Best of Silverfish New Writing 2001-2005 (67-69). Kuala Lumpur: Silverfishbooks.

Bauer-Gatsos, S C. (2002). Reiteration as Resistance: Performativity in the Novels of Charlotte Yonge, George Eliot, and Margaret Oliphant (Doctoral dissertation). Retrieved from ProQuest Digital Dissertations.

Butler, J. (1990) Gender Trouble. New York: Routledge.

Castle, G. (2007). The Blackwell Guide to Literary Theory. Oxford: Blackwell Publishing.

Cean. (2006). The Silk Fan. In Sivagananam, N. (Ed.), 25 Malaysian Short Stories: Best of Silverfish New Writing 2001-2005 (81-88). Kuala Lumpur: Silverfishbooks.

Chin, G. V. S. (2007). New Generation Writings in English: Discursive Conditions and Literary Revival in Malaysia, 1996-2005. In Prescott, D. (Ed.), English in Southeast Asia: Varieties, literacies and literatures (260-287). Newcastle upon Tyne: Cambridge Scholars Publishing.

Gauntlett, D. (2002). Media, Gender and Identity: An Introduction. New York: Routledge.

Goodman, L. (1996). Literature and Gender. New York: Routledge.

Gorney, A. J. (2003). "Truly an 'Awesome' Spectacle”: Gender Performativity, The Closet, and The Alienation Effect in Angels In America (Master dissertation). Retrieved from ProQuest Digital Dissertations.

Koopman, E. (2013). Incestuous rape, abjection, and the colonization of psychic space in Toni Morrison's The Bluest Eye and Shani Mootoo's Cereus Blooms at Night. Journal of Postcolonial Writing, 49(3), 1-25.

Mollon, P. (2008). The Inherent Shame of Sexuality. In Pajaczkowska, C. \& Ward, I. (Eds.), Shame and Sexuality: Psychoanalysis and Visual Culture (23-34). New York: Routledge.

Phillips, A. (2015). Unforbidden Pleasures. Wisconsin: Hamish Hamilton. 
Raihanah, M. M. (2011). New Writings in Malaysia: Issues and Concerns. In Raihanah, M. M., Ruzy, S. H., Noraini, M. Y., \& Zalina, M. L. (Eds.), Gender, Multiculturalism, and Re-visioning: Creating and Fostering Literary Communities (59-69). Selangor: University Putra Malaysia Press.

Ryan, M. (2007). Literary Theory: A Practical Introduction. 2nd ed. Oxford: Blackwell Publishing.

Salter, M. (2013). Grace's story: Prolonged incestuous abuse from childhood into adulthood. Violence Against Women, 19(2), 146-165.

Seidler, V. J. (1995). Reason, Desire, and Male Sexuality. In Caplan, P. (Ed.), The Cultural Construction of Sexuality (82-112). 4th ed. New York: Routledge.

Solomon, J. (2001). Glorying Boy Holes: Masculinity, Submission, and the Performativity of Identity in Coriolanus (Master dissertation). Retrieved from ProQuest Digital Dissertations.

Villani, P. \& Lopes, M. (2014). Mysterious Skin. Springer Link: Sexuality \& Culture, 20(3), 710-718.

Wignesan, T. (1981). Religion as Refuge, or Conflict and Non-Change: The Case of the Malaysian Writer in English. The Journal of Commonwealth Literature, 16 (1), 76-86.

Williams, C. M. (2009). Diaspora Literature: Unexpressed Discourse and Performativity in Dictee and Mulbeery and Peach: Two Women of China (Phd dissertation). Retrieved from ProQuest Digital Dissertations.

Wisdom, J. O. (1992). Freud, Women, and Society. New Jersey: Transaction Publishers. 